\title{
IbM PEMBUATAN BATU ALAM BUATAN MENGGUNAKAN BAHAN BAKU TEMPURUNG, KARANG, PASIR DAN SEMEN
}

\section{IPTEK FOR COMMUNITY PRODUCTION BRAND NATURAL STONE USED RAW MATTERIAL PIECE OF COCONUT SHELL, CORAL STONE, SAND AND PORTLAND CEMENT}

\author{
Oleh: \\ Mekar Ria Pangaribuan, Meilani Belladona \\ Dosen Fakultas Teknik Prodi Teknik Sipil \\ Universitas Ratu Samban, dan Universitas Prof. Dr. Hazairin, S.H. \\ Email: mekarria11@yahoo.com
}

\begin{abstract}
Due to the increasing price and the issue of nature conservation, using natural stone as a building material causes its own problems. The purpose of this activity is to alternate the natural stone material with synthetic materials so that the natural nuances still appear without disturbing the natural. Artifical raw materials used are coconut shell, reefs are widely obtained around their residence. Method of implementation: 1) Collection of raw materials of portland cement, coconut shell, coral and sand, 2) Manufacture of molding beggisting size $15 \mathrm{~cm} \times 30 \mathrm{~cm}$ (22 pieces), $25 \mathrm{~cm} \times 40 \mathrm{~cm}$ (19 pieces), and $10 \mathrm{~cm} \times 40 \mathrm{~cm}$ (1 piece) with $2 \mathrm{~cm}$ of thickness, 3) Preparation of mortar with 2 layer composition, layer $A$ with ratio 2 portland cement: 1 coconut shell: 1 coral, and $B$ with the ratio of mixture 1 portland cemen: 2 sand and sufficient water, 4) Printing by filling the volume of the mold and allowing for 3 days, 5) Opening the mold begisting after casting 3 days, then soaking immersed for 3 days to get desired hardness, 6) Stripping the top layer to get desired texture with an iron grinder, 7) Doing the drying for 1 day and 8) We recommend that teh natural stone is finished with spesial paint for natural stone. The results obtained from the activity are: 1) Obtain the production of artifical natural stone, 2) Perform stripping of the top layer to obtain natural artificial stone texture using $2 \mathrm{~cm}$ thick grinding machine, 3) Conducting product marketing.
\end{abstract}

Keywords: brand natural stone, coral stone, and piece of coconut shell.

\section{PENDAHULUAN}

Batu alam berasal dari dalam perut bumi yang awalnya berbentuk batuan cair yang sangat panas (Ria, 2013). Akibat tekanan yang sangat kuat mendesak ke luar permukaan bumi dan akhirnya menjadi letusan gunung berapi. Setelah mengendap dan membeku menjadi batuan, terdiri dari batuan beku, batuan sedimen dan batuan malihan. Setelah ratusan tahun tercampur dengan mineral-mineral lain menyebabkan variasi dari jenis-jenis batu alam, warna, ataupun corak. Karena itu kita mengenal berbagai jenis batu alam seperti marmer, granit, batu pasir (sandstone), batu sabak slate, batu andesit dan banyak lagi lainnya (Pubi, 1982).

Kehadiran batu alam dimanfaatkan pada bagian finishing dibagian tertentu rumah, khususnya fasad rumah yang akan kelihatan indah, menarik dan akan membuat rumah anda menjadi lebih alami (Wastari, 2002). Selain itu, fasad rumah anda juga akan terhindar 
dari kesan kaku dan akan terlihat lebih luwes, namun tetap harus memperhatikan karakteristiknya sebelum di aplikasikan. Mengaplikasikan batu alam ke dalam bangunan bukan merupakan pekerjaan yang sulit, karena Indonesia punya persediaan bahan ini hingga melimpah. Namun mengingat harganya yang terus mengalami kenaikan dan isu pelestarian alam yang semakin kencang hal ini sering menimbulkan permasalahan tersendiri (Murdock, 1999).

Mitra yang terlibat dalam kegiatan IbM ini adalah tenaga harian bangunan dengan upah perharinya sekitar Rp. 80.000/hari jika kerja selama 8 jam ketika proyek berjalan (selama 4 - 6 bulan, setelah itu menganggur), mitra memiliki keterampilan dalam bidang pertukangan bangunan, biasa bekerja keras. Tempat tinggal mitra merupakan daerah dengan potensi kebun kelapa yang luas, terletak dipesisir Pantai Bengkulu dengan potensi karang mati tersebar sepanjang pantai sebagai bahan baku pembuatan batu alam buatan, dan memiliki kemauan untuk memiliki usaha yang dapat menambah penghasilan keluarga, karena batu alam buatan terus dapat dipakai orang sebagai pemanis bangunan pengganti batu alam yang sangat sulit didapatkan dan mahal harganya.

Justifikasi permasalahan kedua mitra adalah:

1. Bagaimana cara meningkatkan kesejahteraan kedua mitra dengan tetap menggunakan keterampilan mitra dalam ilmu pertukangan bangunan?

2. Bagaimana mendapatkan produksi batu alam buatan melalui keterampilan membuat campuran komposisi tempurung kelapa, batu karang, portland cement ?

3. Bagaimana mendapatkan proses pengupasan lapisan atas batu alam buatan yang telah tercetak dengan menggunakan mesin potong gerinda sebagai bahan finishing dinding untuk mendapatkan tekstur yang diinginkan?

Kegiatan IbM ini akan menghasilkan luaran berupa:

1. Mendapatkan produksi batu alam buatan melalui suatu pembuatan begisting cetakan ukuran yang dibuat adalah 22 buah $(15 \mathrm{~cm} \mathrm{x} 30 \mathrm{~cm}), 19$ buah $(25 \mathrm{~cm} \mathrm{x} 40 \mathrm{~cm})$, dan 1 buah $(10 \mathrm{~cm} \times 40 \mathrm{~cm})$ dengan menggunakan bahan baku tempurung kelapa, batu karang.

2. Melakukan pemotongan batu alam dengan mesin pemotong gerinda mata besi dengan ketebalan $2 \mathrm{~cm}$.

3. Melakukan pemasaran produksi batu alam buatan dan

4. Publikasi ilmiah.

\section{METODE PENGABDIAN}

Khalayak sasaran kegiatan IbM adalah tenaga kerja yang bekerja di proyek sebagai tenaga harian, pelaksanaannya akan dilakukan di Kecamatan Pondok Kumbang Provinsi Bengkulu.

Metode pelaksanaan pembuatan batu alam adalah sebagai berikut:

1. Pengumpulan/penyediaan bahan baku portland cement, tempurung kelapa, batu karang, dan pasir.

2. Tempurung kelapa dan batu karang dibuat butiran dengan ukuran 0,7-1,2 cm secara manual.

3. Semua material cement portland, batu karang, tempurung kelapa dan pasir diperiksa di laboratorium untuk menentukan kepastian ukuran dan zat-zat yang dikandungnya.

4. Pembuatan begisting cetakan ukuran yang dibuat adalah 22 buah $(15 \mathrm{~cm} \mathrm{x} 30 \mathrm{~cm}), 19$ buah $(25 \mathrm{~cm}$ x $40 \mathrm{~cm})$, dan 1 buah $(10 \mathrm{~cm} \mathrm{x} 40 \mathrm{~cm})$. 
5. Membuat bak perendaman dengan menggunakan batako (ukuran $30 \times 16 \times 8 \mathrm{~cm}$ ) yang dibuat sendiri oleh mitra. Ukuran bak perendaman yang direncanakan adalah panjang $130 \mathrm{~cm}$, lebar $80 \mathrm{~cm}$, dan tinggi $35 \mathrm{~cm}$.

6. Membuat adukan A, dengan mencampurkan pecahan 1 batu karang: 1 pecahan batok kelapa, 2 semen dan air sehingga menjadi satu kesatuan. Menaruh adukan A pada cetakan, dengan posisi paling bawah $0,8 \mathrm{~cm}$. Meratakan adukan dengan mengatur letak batok kelapa dan karang agar merata diseluruh cetakan.

7. Membuat adukan B, dengan mencampur 2 pasir, 1 semen dan air sehingga menjadi adukan yang utuh. Menaruh adukan pada cetakan diatas adukan A dengan ukuran 0,8 $\mathrm{cm}$. Meratakan adukan dengan mengatur letak adukan sehingga menjadi rata.

8. Adukan yang telah jadi dibiarkan untuk menjadi kering di cetakan selama \pm 4 hari, untuk mendapatkan kepadatan yang diinginkan.

9. Pengadukan yang menggunakan concrete mixer untuk skala besar, tetapi dapat juga dilakukan dengan cara manual.

10. Pengecoran dilakukan pada begisting yang disediakan

11. Pembukaan begisting dilakukan setelah umur coran 4 hari

12. Setelah coran dibuka, hasil coran direndam dalam air selama 3 hari

13. Pengupasan lapisan atas batu alam untuk mendapatkan tekstur yang diinginkan menggunakan mesin gerinda mesin pemotong batu alam dengan ketebalan $2 \mathrm{~cm}$, kemudian dijemur selama 1 hari.

14. Batu alam tersebut sudah dapat digunakan sebagai batu tempelan dinding untuk bangunan. Batu tempel tersebut pemasangannya sama dengan pemasangan batu alam lainnya

15. Sebaiknya batu alam tersebut difinishing dengan cat khusus batu alam

Metode pendekatan yang dilakukan adalah:

1. Model pendampingan masyarakat: Pendampingan ini juga dilakukan dengan memberikan pelatihan terlebih dahulu kepada mitra, kemudian mendampingi dalam pembuatan cetakan begisting, dan pembuatan produksi batu alam buatan.

2. Model pelatihan dan workshop tentang pembuatan batu alam buatan dari:

a. aspek produksi: Model perencanaan dan perancangan pembuatan produksi batu alam buatan.

b. Aspek Manajemen Usaha: bagaimana melakukan perencanaan usaha dan manajemen keuangannya, kemudian dilakukan juga penyuluhan tentang pemasaran melalui strategi acuan pemasaran (Marketing Mix).

3. Model Tindak Lanjut: Diharapkan kegiatan IbM ini mencapai target berupa luaran yang direncanakan, sehingga permasalahan yang dihadapi mitra bisa diatasi dengan tepat sasaran.

\section{HASIL DAN PEMBAHASAN}

IbM pembuatan batu alam buatan menggunakan bahan baku tempurung, karang, pasir dan semen ini melibatkan mitra dengan pekerjaan sebagai tenaga harian bangunan. Keterampilan mitra bisa dipergunakan dalam pembuatan batu alam buatan ini, disela-sela pekerjaannya sebagai tukang bangunan, dapat juga memproduksi batu alam buatan yang terbuat dari campuran semen, pasir, karang dan tempurung kelapa ini. 
Metode pembuatan batu alam buatan:

A. Persiapan bedeng kerja

Mengadakan material kayu bulat dengan berbagai ukuran, terpal sebagai penutup sebagai bedeng kerja pembuatan batu alam buatan.

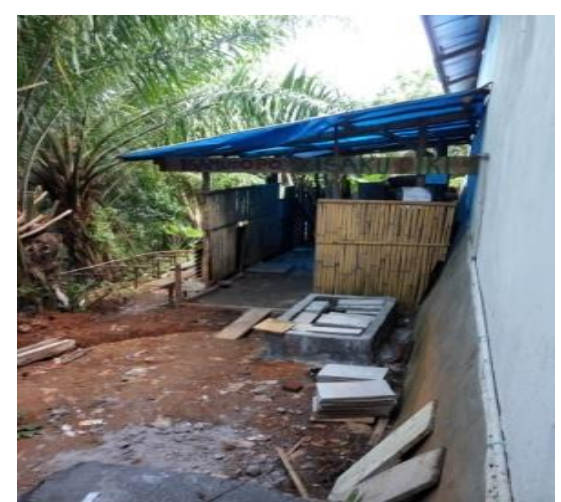

Gambar 1. Persiapan bedeng kerja IbM

B. Persiapan Bahan

- Batu karang: Batu karang ditumbuk halus dengan bodem, lesung atau alat pemecah lainnya hingga menjadi butiran halus seukuran $0,7-1 \mathrm{~cm}$. Kemudian dicuci dengan menggunakan air bersih, hingga terbuang debu, tanah yang menempel.

- Batok kelapa: Dibersihkan dengan pisau serabut yang ada di batok kelapa, kemudian dikikis hingga bersih, juga bagian dalam batok kelapa. Memecahkan batok kelapa dengan modem hingga berukuran 0,7-1,5 cm, dengan posisi pecahan batok kelapa menjadi datar, untuk mendapatkan luasan permukaan yang lebih lebar.

- Semen: Semen yang digunakan adalah semen yang memiliki daya rekat besar, seperti semen padang.

- Pasir: Pasir yang dipakai adalah pasir dari daerah Desa Selolong di Kabupaten Bengkulu Utara, dengan kualitas yang bagus, tidak terlalu halus.

- Air : Air yang dipakai adalah yang layak, misalnya air sumur ataupun dari PDAM.
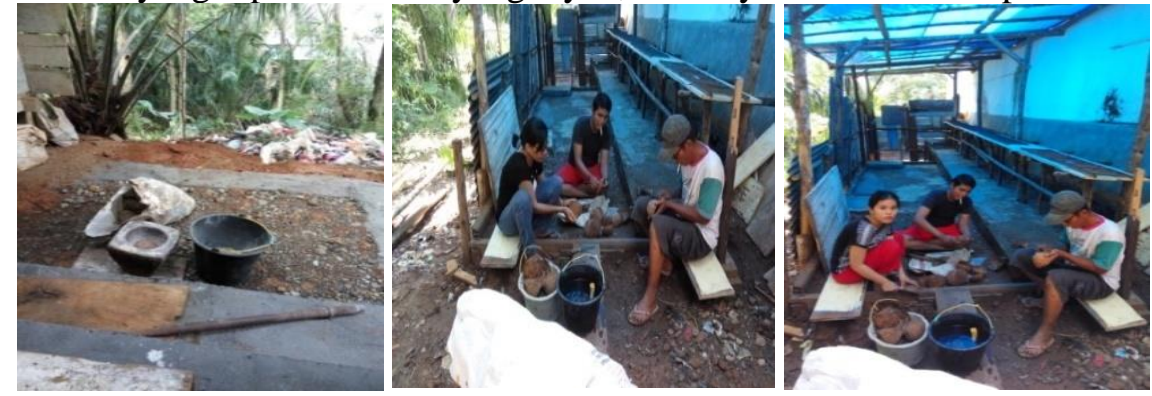

Gambar 2. Persiapan bahan baku batu alam buatan

C. Persiapan Cetakan

- Cetakan untuk batu alam terbuat dari besi siku, seng plat, skrup, paku triplek, meja kerja, dan sebagainya yang dibentuk sedemikan rupa sehingga dapat diletakan di papan kerja, datar, tidak bergerak sebagai tempat adonan batu alam buatan.

- Ukuran cetakan yang dibuat adalah 22 buah (15 cm x $30 \mathrm{~cm}), 19$ buah $(25 \mathrm{~cm} \mathrm{x} 40$ $\mathrm{cm})$, dan 1 buah $(10 \mathrm{~cm} \mathrm{x} 40 \mathrm{~cm})$. 


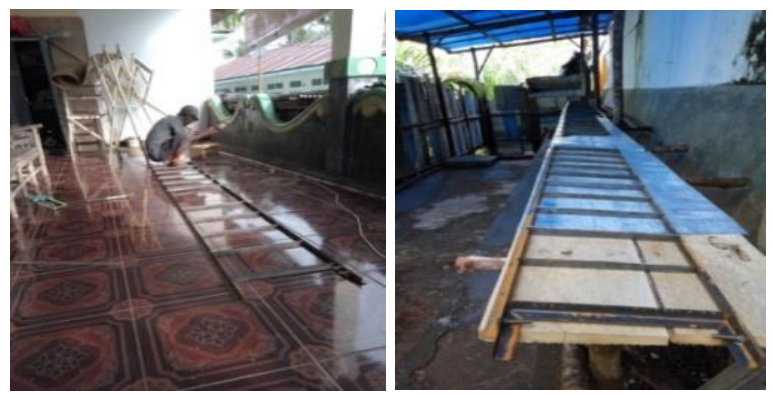

Gambar 3. Persiapan begisting cetakan batu alam buatan

D. Pembuatan Bak Perendaman

- Membuat bak perendaman dengan menggunakan batako (ukuran $30 \mathrm{~cm}$ x $16 \mathrm{~cm}$ x 8 $\mathrm{cm})$ yang dibuat sendiri oleh mitra.

- Ukuran bak perendaman yang direncanakan adalah panjang $130 \mathrm{~cm}$, lebar $80 \mathrm{~cm}$, dan tinggi $35 \mathrm{~cm}$.

- Memplester bak perendaman, kemudian munguji coba untuk memastikan tidak ada kebocorannya.

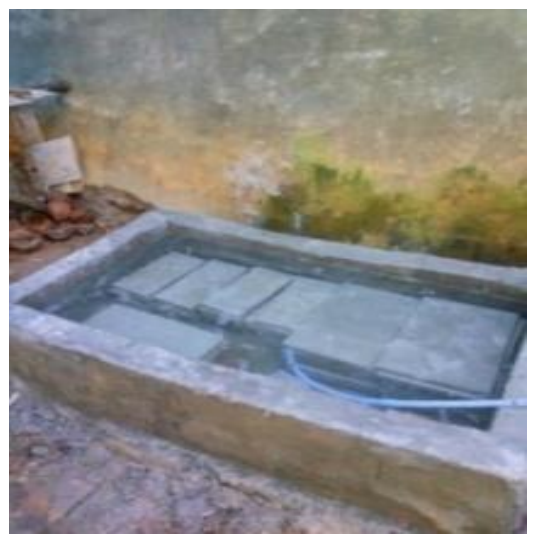

Gambar 4. Pembuatan bak perendaman batu alam buata

E. Pembuatan Adukan dan pencetakan

- Membuat adukan A, dengan mencampurkan pecahan batu karang, pecahan batok kelapa, dan air sehingga menjadi satu kesatuan.

- Menaruh adukan A pada cetakan, dengan posisi paling bawah 0,8 cm.

- Meratakan adukan dengan mengatur letak batok kelapa agar merata diseluruh cetakan.

- Membuat adukan B, dengan mencampur pasir, semen dan air sehingga menjadi adukan yang utuh.

- Menaruh adukan pada cetakan diatas adukan A dengan ukuran 0,8 cm.

- Meratakan adukan dengan mengatur letak adukan sehingga menjadi rata.

- Adukan yang telah jadi dibiarkan untuk menjadi kering di cetakan selama \pm 2 hari, untuk mendapatkan kepadatan yang diinginkan. 

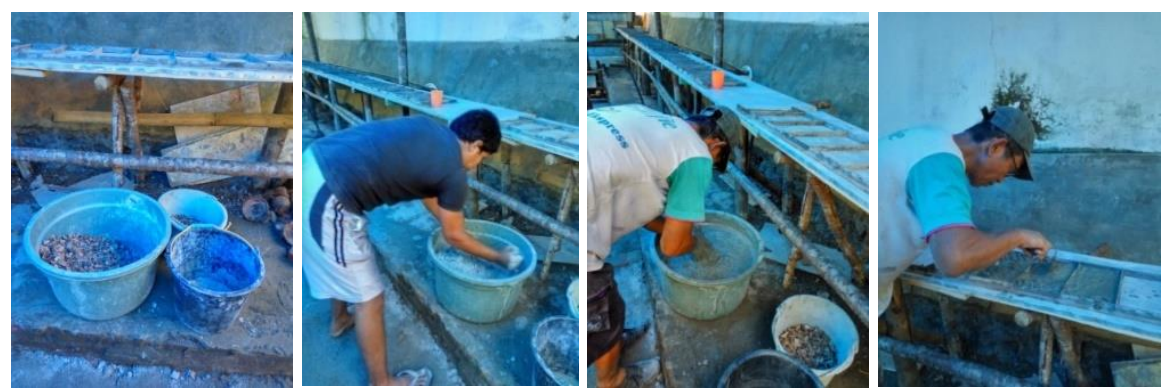

Gambar 5. Proses Pengadukan Coran Adukan A pada Batu Alam Buatan

\section{F. Perendaman}

- Bak perendaman dibuat sendiri oleh mitra dengan menggunakan cetakan batako (ukuran $30 \times 16 \times 8 \mathrm{~cm}$ ) dengan ukuran bak perendaman panjang $130 \mathrm{~cm}$, lebar 80 $\mathrm{cm}$ dan tinggi $35 \mathrm{~cm}$.

- Bak perendaman diplester dengan rapi dan duji untuk melihat kebocoran.

- Batu alam buatan yang telah dicetak dan didiamkan selama \pm 2 hari, kemudian dilepaskan dari cetakan dan disusun rapi dalam bak perendaman yang telah terisi air penuh.

- Perendaman dilakukan selama \pm 3 hari, untuk mendapatkan kekuatan dari batu alam buatan yang dihasilkannya.
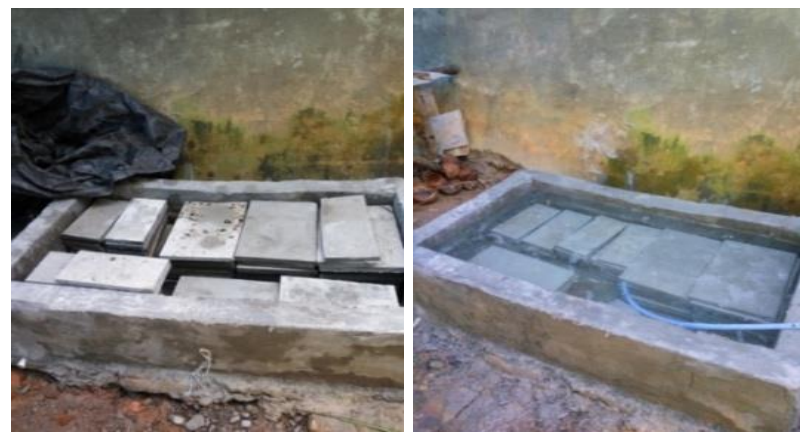

Gambar 6. Proses perendaman batu alam buatan pada bak perendaman

G. Menggosok dan mengeringkan Batu Alam Buatan

- Batu alam yang telah direndam, selanjutnya dilakukan penggosokan dengan menggunakan gerinda.
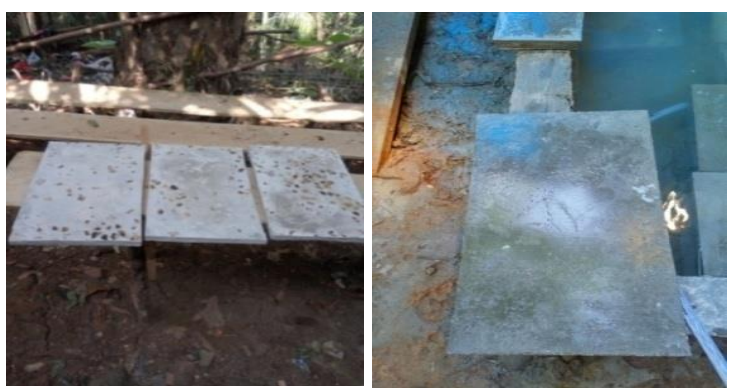

Gambar 7. Proses pernggosokan dan penjemuran batu alam buatan 
H. Batu Alam buatan

Setelah mengalami pengosokan dengan menggunakan gerinda mata gerinda yang besi, didapatkanlah tekstur berbintik bintik dengan ukuran batu alam yang telah ditentukan.
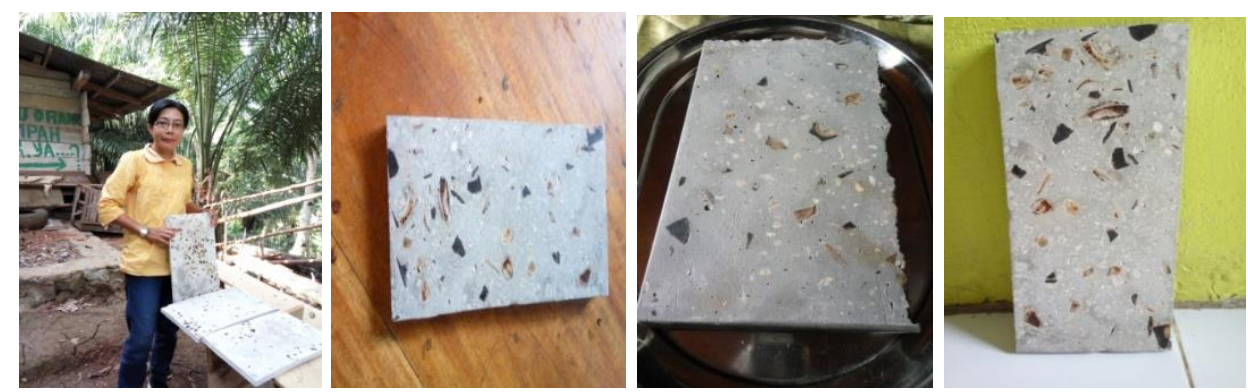

Gambar 8. Batu alam buatan dari bahan baku tempurung kelapa dan batu karang

\section{Proses pembuatan batu alam buatan}

Pembuatan batu alam buatan menggunakan pecahan batu karang (BK), pecahan tempurung kelapa (TK), semen (PC), pasir (Pr), dan air.

Potongan melintang adukan cetakan :

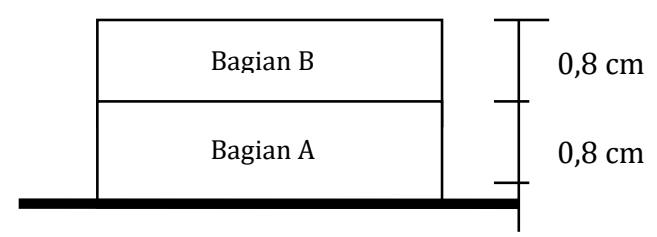

Tebal batu alam $=16 \mathrm{~mm}$

Tebal lapisan $\mathrm{A}=8 \mathrm{~mm}$

Tebal lapisan $\mathrm{B}=8 \mathrm{~mm}$

Ukuran cetakan yang dibuat adalah 22 buah $(15 \mathrm{~cm} \times 30 \mathrm{~cm}), 19$ buah $(25 \mathrm{~cm} \times 40$ $\mathrm{cm})$, dan 1 buah $(10 \mathrm{~cm} \times 40 \mathrm{~cm})$.

\section{Untuk 42 buah batu alam buatan membutuhkan:}

A. Lapisan A tebal $8 \mathrm{~mm}$

- Karang ukuran $10 \mathrm{~mm}$

$=11.920$ gram

- Tempurung kelapa

$=2.336$ gram

- Semen

$=4.400$ gram

- Air

$=10$ liter

Atau perbandingan $1 \mathrm{BK}: 1 \mathrm{TK}: 2 \mathrm{PC}$

B. Lapisan B tebal $8 \mathrm{~mm}$

$\begin{array}{ll}- \text { Pasir } & =6.400 \text { gram } \\ - \text { Semen } & =3.200 \text { gram } \\ \text { - Air } & =10 \text { liter }\end{array}$

Atau perbandingan $2 \mathrm{Psr}: 1 \mathrm{Pc}$

C. Berat batu alam buatan/buah $=2.000 \mathrm{Gram}=2 \mathrm{Kg}$. 


\section{Kebutuhan Batu Alam Buatan untuk $1 \mathrm{M}^{2}$}

Cetakan A :

$$
\begin{array}{ll}
0,15 \mathrm{~m} \times 0,30 \mathrm{~m} \times 0,08 \mathrm{~m} \times 22 \mathrm{buah} & =0,0792 \mathrm{~m}^{3} \\
0,25 \times 0,40 \mathrm{~m} \times 0,08 \mathrm{~m} \times 19 \mathrm{buah} & =0,152 \mathrm{~m}^{3} \\
0,10 \mathrm{~m} \times 0,40 \mathrm{~m} \times 0,08 \mathrm{~m} \times 1 \mathrm{buah} & =0,0032 \mathrm{~m}^{3} \\
\hline \text { Total } & =0,2344 \mathrm{~m}^{3}
\end{array}
$$

Cetakan B : $\quad 0,15 \mathrm{~m} \times 0,30 \mathrm{~m} \times 0,08 \mathrm{~m} \times 22$ buah $=0,0792 \mathrm{~m}^{3}$

$$
\begin{array}{ll}
0,25 \times 0,40 \mathrm{~m} \times 0,08 \mathrm{~m} \times 19 \mathrm{buah} & =0,152 \mathrm{~m}^{3} \\
0,10 \mathrm{~m} \times 0,40 \mathrm{~m} \times 0,08 \mathrm{~m} \times 1 \mathrm{buah} & =0,0032 \mathrm{~m}^{3} \\
\hline \text { Total } & =0,2344 \mathrm{~m}^{3}
\end{array}
$$

Maka Cetakan A + Cetakan B $=0,4688 \mathrm{~m}^{3}$

Untuk $1 \mathrm{~m}^{2}$ dibutuhkan $=\frac{1}{0,4688 \mathrm{~m}^{3}}=48$ buah batu alam buatan

- Asumsi Pasir untuk $1 \mathrm{M}^{3}$ adalah $1.300 \mathrm{Kg}=1.300 .000 \mathrm{Gram}$

Kebutuhan pada batu alam 6.400 gram $=\frac{6400 \mathrm{gram}}{1300000 \mathrm{gram}}=0,00492 \mathrm{~m}^{3}$

- Asumsi karang untuk $1 \mathrm{M}^{3}$ adalah $980 \mathrm{Kg}=980.000 \mathrm{Gram}$

Kebutuhan pada batu alam 11.920 gram $=\frac{11920 \mathrm{gram}}{980000 \mathrm{gram}}=0,0122 \mathrm{~m}^{3}$

- Asumsi tempurung kelapa untuk $1 \mathrm{M}^{3}$ adalah $980 \mathrm{Kg}=980.000 \mathrm{Gram}$

Kebutuhan pada batu alam 2.336 gram $=\frac{2336 \mathrm{gram}}{980000 \mathrm{gram}}=0,00238 \mathrm{~m}^{3}$

Kebutuhan semen batu alam $(2336 \mathrm{gram}+3200 \mathrm{gram})=\frac{5536 \mathrm{gram}}{1000 \mathrm{gram}}=5,536 \mathrm{Kg}$

\section{Asumsi Biaya per Buah Batu Alam Buatan}

\begin{tabular}{llll} 
Semen & $=5,536 \mathrm{Kg} \times \mathrm{Rp} .1 \cdot 200,-$ & $=$ & $\mathrm{Rp} .6 \cdot 643,-$ \\
Pasir & $=0,00492 \mathrm{M}^{3} \times \mathrm{Rp} .200 .000,-$ & & $\mathrm{Rp} .984,-$ \\
Tempurung kelapa & $=0,00238 \mathrm{M}^{3} \times \mathrm{Rp} .100 .000,-$ & $=$ & $\mathrm{Rp} .238,-$ \\
Karang & $=0,0122 \mathrm{M}^{3} \times \mathrm{Rp} .250 .000,-$ & $=$ & Rp. 3.050,- \\
\cline { 2 - 5 } & Total & $=$ & Rp.10.915,- \\
& dibulatkan & $=$ & Rp.11.000,-
\end{tabular}

Kebutuhan untuk $1 M^{2}$ adalah 48 buah x Rp. 11.000,- = Rp. 528.000,-

\section{Analisa Biaya Upah Paving Block}

1 hari produksi paving block mendapatkan 48 buah batu alam dengan rincian sebagai berikut:

1 orang pekerja $x$ Rp. 100.000,- = Rp. 100.000,-

Upah kerja untuk 1 buah batu alam $=\frac{R p \cdot 100 \cdot 000,-}{48 b u a h}=$ Rp. $2.000,-$

Jadi total harga paving block per buah:

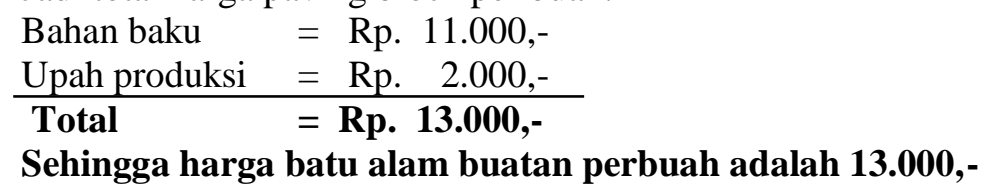




\section{Pembahasan:}

Batu alam berasal dari dalam perut bumi yang awalnya berbentuk batuan cair yang sangat panas. Akibat tekanan yang sangat kuat mendesak ke luar permukaan bumi dan akhirnya menjadi letusan gunung berapi. Setelah mengendap dan membeku menjadi batuan, terdiri dari batuan beku, batuan sedimen dan batuan malihan. Setelah ratusan tahun tercampur dengan mineral-mineral lain menyebabkan variasi dari jenis-jenis batu alam, warna, ataupun corak. Karena itu kita mengenal berbagai jenis batu alam seperti marmer, granit, batu pasir (sandstone), batu sabak (slate), batu andesit dan banyak lagi lainnya.

Industri batu alam: penambangan batu alam di Indonesia umumnya dilakukan secara tradisional dan tidak banyak menggunakan alat-alat berat. Terkecuali batu jenis marmer dan granit yang sebagian penambangannya dikuasai secara besar-besaran telah dilakukan secara modern (Wadiyana, 2009). Sedangkan jenis batu alam lainnya sangat mengandalkan tenaga manusia ataupun terbatas sampai pada pemakaian alat berat back-hoe dan dinamit. Setelah batu alamnya diambil, maka dibawa ke lokasi pemrosesan atau biasa disebut pabrik pemotongan. Di pabrik ini, proses yang dilakukan biasanya berbentuk membelah batu menjadi lembaran-lembaran dan dipotong menjadi bentuk persegi, dan sebagian lagi memerlukan proses finishing. Jenis finishing dapat berupa pemolesan di mana satu sisanya menjadi mengkilat, atau dibakar supaya permukaannya menjadi kasar atau sandblasting dan macam-macam jenis finishing lainnya.

Industri batu alam buatan: Dikarenakan batu alam adalah bahan alam yang tidak dapat diperbaharui, dan sekarang sulit untuk didapatkan dengan harga yang semakin bersaing, industri batu alam buatan mulai berkembang, yang menggunakan campuran semen, pasir dan bahan additive/tambahan lainnya, misalnya yang dilakukan pada IbM ini, yaitu menggunakan campuran pecahan tempurung kelapa dan batu karang mata. Batu alam yang dihasilkan memiliki tekstur yang alami, dengan ukuran yang saat ini baru ada tiga yaitu 15 x $30 \mathrm{~cm}, 25 \times 40 \mathrm{~cm}$, dan 10 x $40 \mathrm{~cm}$. Batu alam buatan ini digunakan sebagai bahan finishing untuk dinding, dengan harapan dapat digemari oleh masyarakat dan mulai dikenalkan dengan mengikuti pameran dan pamflet yang disebar. Aplikasi batu alam dapat dipergunakan untuk dinding maupun lantai bangunan ataupun landscape. Dapat ditempel, disusun ataupun sekedar ditaruh. Pemeliharaan batu alam adalah jangan kena saos, sikatcoating anti lumut. Pemakaian batu alam memang sebaiknya menggunakan jasa perancang (konsultan arsitek sehingga didapatkan pemilihan warna, ukuran dan jenis batu yang sesuai dengan bentuk arsitektur bangunan, selera pemilik rumah dan fungsinya sendiri. Tetapi memang di Indonesia jasa arsitek masih digunakan secara terbatas sehingga seringkali pemilik rumah yang menentukan spesifikasi finishing bangunan seperti warna cat, genting, sanitaire termasuk batu alam. Apalagi apabila sifatnya bukan membangun baru tetapi hanya renovasi saja.

Ada beberapa tips atau petunjuk praktis dalam menentukan batu alam yang akan digunakan:

1. Murah bukan berarti jelek: jangan memilih batu dengan pertimbangan harga lebih mahal. Batu yang mahal bukan berati selalu lebih baik, lebih kuat dan lebih indah. Faktor harga biasanya ditentukan oleh biaya processing yang berbeda, biaya angkutan yang lebih jauh dan sedang trend. Jadi apabila batu yang Anda sukai ternyata murah jangan menjadi segan untuk membelinya atau sebaliknya. Sesuaikan dengan kebutuhan.

2. Batu memiliki sifat/karakteristik sifat porous: beberapa jenis batu memang memiliki sifat porous (mudah meresap), jadi jangan digunakan untuk tempat-tempat yang sangat lembab. Tanyakan dahulu kepada penjual apakah batu yang Anda minati memiliki sifat agak, sangat atau malah tidak porous. 
3. Homogenitas corak dan warna: batu tidak mungkin $100 \%$, batu alam bukanlah berasal dari bahan cetakan, tetapi hanya diproses dibelah dan dipotong (atau diukir). Karena itu pada saat Anda menimbang-nimbang jenis batu yang sesuai dengan keinginan Anda, gunakan setidaknya 3 buah batu (yang berjenis sama) sebagai sampel (berbagai sumber)

Melalui kegiatan IbM pembuatan batu alam buata dengan bahan baku tempurung kelapa, dan karang ini diharapkan mitra sebagai sasaran program dapat terus melakukan pengembangan inovasi corak dan model batu alam yang dihasilkan. Selain itu kami sedang melakukan proses ijin usaha "Izakuiki" bekerjasama dengan Dinas Perindustrian Provinsi Bengkulu untuk dapat dilakukan pembinaan dan ikut serta dalam kegiatan pameran, dan target kedepan ingin mengikuti EXPO di Jakarta Convention Center yang diadakan di Jakarta bulan November 2017 ini. Semoga kegiatan IbM ini dapat terus berlangsung dengan terus meningkatkan produksi dan mengelola manajemen kegiatan usaha agar dapat bertahan dan berkelanjutan menuju industri kegiatan masyarakat yang berkelanjutan.

\section{KESIMPULAN DAN SARAN}

\section{Kesimpulan}

1. Pada IbM pembuatan batu alam buatan, dimana pada satu kali proses pencetakan akan mendapatkan 42 buah batu alam buatan menggunakan bahan baku tempurung, karang, pasir, dan semen dengan menggunakan cetakan ukuran $15 \mathrm{~cm} \mathrm{x} 30 \mathrm{~cm}$ (22 buah), 25 $\mathrm{cm}$ x $40 \mathrm{~cm}$ (19 buah), dan $10 \mathrm{~cm}$ x $40 \mathrm{~cm}$ (1 buah) dengan ketebalan $2 \mathrm{~cm}$.

2. Pembuatan adukan dan pencetakan adalah:

a. Membuat adukan A, dengan mencampurkan pecahan batu karang (11.920 gram), pecahan batok kelapa (4.400 gram), semen (2.336 gram) dan 10 liter air sehingga menjadi satu kesatuan. Menaruh adukan A pada cetakan, dengan posisi paling bawah $0,8 \mathrm{~cm}$. Meratakan adukan dengan mengatur letak batok kelapa agar merata diseluruh cetakan.

b. Membuat adukan B, dengan mencampur pasir (6.400 gram), semen (3.200 gram) dan 10 liter air sehingga menjadi adukan yang utuh. Menaruh adukan pada cetakan di atas adukan A dengan ukuran 0,8 cm. Meratakan adukan dengan mengatur letak adukan sehingga menjadi rata.

c. Adukan yang telah jadi dibiarkan untuk menjadi kering di cetakan selama \pm 4 hari, untuk mendapatkan kepadatan yang diinginkan.

d. Proses perendaman dilakukan sekitar 3 hari untuk mendapatkan kekerasan batu alam yang diinginkan, kemudian dilakukan penggosokan dengan menggunakan mesin gerinda mata besi sehingga akan timbul tekstur sayak/tempurung kelapa dan bintik-bintik batu karang yang akan bersinar ketika terkena cahaya matahari dan lampu. Batu alam buatan ini sebaiknya digunakan pada dinding ruangan, untuk menambah keindahan ruangan.

3. Dengan memanfaatkan tempurung kelapa dan batu karang yang ada di Bengkulu dapat dibuatkan batu alam buatan yang memiliki tekstur dengan harga batu alam buatan 13.000/buahnya.

\section{Saran}

Diharapkan kepada mitra untuk terus bersemangat melaksanakan pembuatan batu alam buatan ini, sehingga kemampuan mereka lebih terampil lagi, dan perlu kemauan kuat untuk dapat menjadi wirausaha baru. 


\section{DAFTAR PUSTAKA}

Ria, M.P., 2013, Pengaruh Batu Cadas (Batu Trass) sebagai Bahan Pembentuk Beton terhadap Kuat Tekan Beton, Jurnal Inersia ISSN 2086-9045, Vol. 5 No. 2, Universitas Bengkulu.

Murdock, L.J., 1999, Bahan dan Praktek Beton, Erlangga, Jakarta.

Pubi, 1982, Persyaratan Umum Bahan Bangunan di Indonesia, Pusat Penelitian dan Pengembangan Permukiman, Pusat Penelitian dan Pengembangan Pekerjaan Umum, Bandung.

Wastari, S., 2002, Evaluasi Mutu Beton, Pusat Pengembangan Penataran guru Teknologi Bandung, Bandung.

Wadiyana, 2009, Kajian Karateristik Batu Alam Lokal Kabupaten Gunung Kidul Sebagai Alternatif Pengganti Batu Merah Pejal untuk Pembangunan dan Rehabilitasi Rumah Sederhana, Tesis Universitas Sebelas Maret, Surakarta. 